\title{
Strong convergence theorems for common solutions of a family of nonexpansive mappings and an accretive operator
}

Peng Cheng ${ }^{1}$ and Huilian $\mathrm{Wu}^{2^{*}}$

*Correspondence:
hbwuhl@yeah.net
${ }^{2}$ College of Science, Hebei
University of Engineering, Handan,
056038 , China
Full list of author information is
available at the end of the article

available at the end of the article

\begin{abstract}
In this paper, common solutions of a family of nonexpansive mappings and an accretive operator are investigated based on a viscosity iterative method. Strong convergence theorems for common solutions are established in a Banach space. MSC: 47H09; 47J05

Keywords: accretive operator; iterative scheme; fixed point; nonexpansive mapping; strong convergence
\end{abstract}

\section{Introduction}

Fixed point theory has emerged as an effective and powerful tool for studying a wide class of problems which arise in economics, finance, image reconstruction, ecology, transportation, network, elasticity and optimization; see [1-12] and the references therein. The computation of solutions is important in the study of many real world problems. The wellknown convex feasibility problem which captures applications in various disciplines such as image restoration and radiation therapy treatment planning is to find a point in the intersection of common fixed point sets of a family of nonlinear mappings; see, for example, [13-24] and the references therein.

The aim of this paper is to investigate a common solution problem of a family of nonexpansive mappings and an accretive operator based on a viscosity iterative method. The organization of this article is as follows. In Section 2, we provide some necessary preliminaries. In Section 3, a viscosity iterative method is discussed. Strong convergence theorems of common solutions are established in a reflexive and strictly convex Banach space $E$ which enjoys weakly continuous duality mappings.

\section{Preliminaries}

Throughout this paper, we assume that $E$ is a real Banach space. Let $C$ be a nonempty, closed and convex subset of $E$, and let $T: C \rightarrow C$ be a mapping. A point $x \in C$ is a fixed point of $T$ provided $T x=x$. Denote by $F(T)$ the set of fixed points of $T$; that is, $F(T)=\{x \in$ $C: T x=x\}$.

Recall that $T: C \rightarrow C$ is nonexpansive iff

$$
\|T x-T y\| \leq\|x-y\|, \quad \forall x, y \in C .
$$

( 2013 Cheng and Wu; licensee Springer. This is an Open Access article distributed under the terms of the Creative Commons Attribution License (http://creativecommons.org/licenses/by/2.0), which permits unrestricted use, distribution, and reproduction in any medium, provided the original work is properly cited. 
$T: C \rightarrow C$ is a contraction iff there exists a constant $\alpha \in(0,1)$ such that

$$
\|f(x)-f(y)\| \leq \alpha\|x-y\|, \quad \forall x, y \in C .
$$

We use $\Pi_{C}$ to denote the collection of all contractions on $C$. That is, $\Pi_{C}:=\{f \mid f: C \rightarrow$ $C$ a contraction\}.

The Picard iterative algorithm is an efficient algorithm to study contractions. However, the Picard iterative algorithm fails to converge to fixed points of nonexpansive mappings even that their fixed point sets are not empty. One classical way to study nonexpansive mappings is to use contractions to approximate a nonexpansive mapping. More precisely, take $t \in(0,1)$ and define a mapping $T_{t}: C \rightarrow C$ by

$$
T_{t} x=t f(u)+(1-t) T x, \quad \forall x \in C,
$$

where $u \in C$ is a fixed element and $f$ is a contraction on $C$ with the constant $\alpha$. It is easy to see that $T_{t}$ is a contraction with the constant $\alpha$. Indeed, we have the following:

$$
\begin{aligned}
\left\|T_{t} x-T_{t} y\right\| & \leq t\|f(x)-f(y)\|+(1-t)\|T x-T y\| \\
& \leq t \alpha\|x-y\|+(1-t)\|x-y\| \\
& =[1-t(1-\alpha)]\|x-y\| .
\end{aligned}
$$

Banach's contraction mapping principle guarantees that $T_{t}$ has a unique fixed point. We denote the unique fixed point by $x_{t}$. Reich [25] proved that if $E$ is a uniformly smooth Banach space, then $x_{t}$ strongly converges to a fixed point of $T$, and the limit defines the (unique) sunny nonexpansive retraction from $\Pi_{C}$ onto $F(T)$. Recently, Xu [26] further proved that the above results still hold in reflexive Banach spaces which have weakly continuous duality mappings.

Recall that the normal Mann iterative algorithm was introduced by Mann in 1953. Since then the construction of fixed points for nonexpansive mappings via the normal Mann iterative algorithm has been extensively investigated by many authors.

The normal Mann iterative algorithm generates a sequence $\left\{x_{n}\right\}$ in the following manner:

$$
\forall x_{1} \in C, \quad x_{n+1}=\left(1-\alpha_{n}\right) x_{n}+\alpha_{n} T x_{n}, \quad \forall n \geq 1,
$$

where the sequence $\left\{\alpha_{n}\right\}$ is in the interval $(0,1)$. If $T$ is a nonexpansive mapping with a fixed point and the control sequence $\left\{\alpha_{n}\right\}$ is chosen so that $\sum_{n=0}^{\infty} \alpha_{n}\left(1-\alpha_{n}\right)=\infty$, then the sequence $\left\{x_{n}\right\}$ generated by the normal Mann iterative algorithm converges weakly to a fixed point of $T$ (this is also valid in a uniformly convex Banach space with the Fréchet differentiable norm). Since the Mann iterative algorithm only has weak convergence in infinite dimension spaces, many authors tried to modify the normal Mann iteration algorithm to have strong convergence for nonexpansive mappings. 
Kim and $\mathrm{Xu}$ [27] considered the following iterative algorithm.

$$
\left\{\begin{array}{l}
x_{0} \in C \quad \text { arbitrarily chosen, } \\
y_{n}=\beta_{n} x_{n}+\left(1-\beta_{n}\right) T x_{n}, \\
x_{n+1}=\alpha_{n} u+\left(1-\alpha_{n}\right) y_{n}, \quad n \geq 0
\end{array}\right.
$$

where $T$ is a nonexpansive mapping of $C$ into itself, $u \in C$ is a given point, $\left\{\alpha_{n}\right\}$ and $\left\{\beta_{n}\right\}$ are two real number sequences in $(0,1)$. They proved that the sequence $\left\{x_{n}\right\}$ generated by the above iterative algorithm strongly converges to a fixed point of the mapping $T$ provided that the control sequences $\left\{\alpha_{n}\right\}$ and $\left\{\beta_{n}\right\}$ satisfy appropriate conditions.

Recently, many authors have studied the following convex feasibility problem (CFP): $x \in \bigcap_{i=1}^{N} C_{i}$, where $N \geq 1$ is an integer, and each $C_{i}$ is assumed to be the fixed point set of a nonexpansive mapping $T_{i}, i=1,2, \ldots, N$. There is a considerable investigation on CFP in the setting of Hilbert spaces which captures applications in various disciplines such as image restoration [28], computer tomography [29] and radiation therapy treatment planning [30].

In this paper, we consider the mapping $W_{n}$ defined by

$$
\begin{aligned}
& U_{n, n+1}=I, \\
& U_{n, n}=\gamma_{n} T_{n} U_{n, n+1}+\left(1-\gamma_{n}\right) I, \\
& U_{n, n-1}=\gamma_{n-1} T_{n-1} U_{n, n}+\left(1-\gamma_{n-1}\right) I, \\
& \vdots \\
& U_{n, k}=\gamma_{k} T_{k} U_{n, k+1}+\left(1-\gamma_{k}\right) I, \\
& U_{n, k-1}=\gamma_{k-1} T_{k-1} U_{n, k}+\left(1-\gamma_{k-1}\right) I, \\
& \vdots \\
& U_{n, 2}=\gamma_{2} T_{2} U_{n, 3}+\left(1-\gamma_{2}\right) I, \\
& W_{n}=U_{n, 1}=\gamma_{1} T_{1} U_{n, 2}+\left(1-\gamma_{1}\right) I,
\end{aligned}
$$

where $\left\{\gamma_{1}\right\},\left\{\gamma_{2}\right\}, \ldots$ are real numbers such that $0 \leq \gamma_{n} \leq 1$ and $T_{1}, T_{2}, \ldots$ are nonexpansive mappings of $C$ into itself. Nonexpansivity of each $T_{i}$ ensures the nonexpansivity of $W_{n}$.

We have the following lemmas which are important to prove our main results.

Lemma 2.1 [31] Let $C$ be a nonempty closed convex subset of a strictly convex Banach space E. Let $T_{1}, T_{2}, \ldots$ be nonexpansive mappings of $C$ into itself such that $\bigcap_{n=1}^{\infty} F\left(T_{n}\right) \neq \emptyset$ and let $\gamma_{1}, \gamma_{2}, \ldots$ be real numbers such that $0<\gamma_{n} \leq b<1$, where $b$ is some real number, for any $n \geq 1$. Then, for every $x \in C$ and $k \in N$, the limit $\lim _{n \rightarrow \infty} U_{n, k} x$ exists.

Using Lemma 2.1, one can define the mapping $W$ of $C$ into itself as follows.

$$
W x=\lim _{n \rightarrow \infty} W_{n} x=\lim _{n \rightarrow \infty} U_{n, 1} x, \quad \forall x \in C .
$$

Such a mapping $W$ is called the $W$-mapping generated by $T_{1}, T_{2}, \ldots$ and $\gamma_{1}, \gamma_{2}, \ldots$ Throughout this paper, we will assume that $0<\gamma_{n} \leq b<1$ for all $n \geq 1$. 
Lemma 2.2 [31] Let $C$ be a nonempty closed convex subset of a strictly convex Banach space E. Let $T_{1}, T_{2}, \ldots$ be nonexpansive mappings of $C$ into itself such that $\bigcap_{n=1}^{\infty} F\left(T_{n}\right) \neq \emptyset$ and let $\gamma_{1}, \gamma_{2}, \ldots$ be real numbers such that $0<\gamma_{n} \leq b<1$ for any $n \geq 1$. Then $F(W)=$ $\bigcap_{n=1}^{\infty} F\left(T_{n}\right)$.

Let $I$ denote the identity operator on $E$. An operator $A \subset E \times E$ with domain $D(A)=\{z \in$ $E: A z \neq \emptyset\}$ and range $R(A)=\bigcup\{A z: z \in D(A)\}$ is said to be accretive if for each $x_{i} \in D(A)$ and $y_{i} \in A x_{i}, i=1,2$, there exists $j\left(x_{1}-x_{2}\right) \in J\left(x_{1}-x_{2}\right)$ such that

$$
\left\langle y_{1}-y_{2}, j\left(x_{1}-x_{2}\right)\right\rangle \geq 0
$$

An accretive operator $A$ is said to be $m$-accretive if $R(I+r A)=E$ for all $r>0$. In a real Hilbert space, an operator $A$ is $m$-accretive if and only if $A$ is maximal monotone. In this paper, we use $A^{-1}(0)$ to denote the set of zero points of $A$. Interest in accretive operators, which is an important class of nonlinear operators, stems mainly from their firm connection with equations of evolution.

For an accretive operator $A$, we can define a nonexpansive single-valued mapping $J_{r}$ : $R(I+r A) \rightarrow D(A)$ by $J_{r}=(I+r A)^{-1}$ for each $r>0$, which is called the resolvent of $A$. One of classical methods of studying the problem $0 \in A x$, where $A \subset E \times E$ is an accretive operator, is the following:

$$
x_{0} \in E, \quad x_{n+1}=J_{r_{n}} x_{n}, \quad \forall n \geq 0,
$$

where $J_{r_{n}}=\left(I+r_{n} A\right)^{-1}$ and $\left\{r_{n}\right\}$ is a sequence of positive real numbers. Recently, different regularization iterative methods have been employed to treat zero points of accretive operators in the framework of Banach spaces; see [32-36] and the references therein.

In this paper, we investigate common fixed point problems of a family of nonexpansive mappings generated in (2.1) and a zero point problem of an accretive operator based on a viscosity approximation method. Strong convergence theorems of common fixed points are established in a Banach space. In order to prove our main results, we need the following definitions and lemmas.

Recall that if $C$ and $D$ are nonempty subsets of a Banach space $E$ such that $C$ is nonempty closed convex and $D \subset C$, then map $Q: C \rightarrow D$ is sunny provided that $Q(x+t(x-Q(x)))=$ $Q(x)$ for all $x \in C$ and $t \geq 0$ whenever $x+t(x-Q(x)) \in C$. A sunny nonexpansive retraction is a sunny retraction, which is also nonexpansive. Sunny nonexpansive retractions play an important role in our argument. They are characterized as follows: If $E$ is a smooth Banach space, then $Q: C \rightarrow D$ is a sunny nonexpansive retraction if and only if the following inequality holds:

$$
\langle x-Q x, J(y-Q x)\rangle \leq 0 \quad \text { for all } x \in C \text { and } y \in D
$$

Chen and Zhu [34] showed that if $E$ is a reflexive Banach space and has a weakly continuous duality, then there is a sunny nonexpansive retraction from $\Pi_{C}$ onto $F(T)$ and it can be constructed as follows.

Lemma 2.3 [32] Let E be a reflexive Banach space which has a weakly continuous duality mapping $J_{\varphi}(x)$. Let $C$ be closed convex subset of $E$ and let $T: C \rightarrow C$ be a nonexpansive 
mapping. Let $f: C \rightarrow C$ be a contractive mapping with $F(f) \neq \emptyset$. For any $t \in(0,1)$, let $\left\{x_{t}\right\}$ be defined by $x_{t}=t f\left(x_{t}\right)+(1-t) T x_{t}$, where $T$ is a nonexpansive mapping. Then $T$ has a fixed point if and only if $\left\{x_{t}\right\}$ remains bounded as $t \rightarrow 0^{+}$and, in this case, $\left\{x_{t}\right\}$ converges, as $t \rightarrow 0^{+}$, strongly to a fixed point of $T$.

Lemma 2.4 Under the condition of Lemma 2.3, we define the mapping $Q: \Pi_{C} \rightarrow F(T)$ by

$$
Q(f):=\lim _{t \rightarrow 0} x_{t}, \quad f \in \Pi_{C} .
$$

Then the mapping $Q$ is a sunny nonexpansive retraction from $\Pi_{C}$ onto $F(T)$.

Proof From Theorem 3.1 of [34], for all $t \in(0,1)$ and $p \in F(T)$, we have

$$
\left\langle x_{t}-f\left(x_{t}\right), J_{\varphi}\left(x_{t}-p\right)\right\rangle \leq 0 \text {. }
$$

Letting $t \rightarrow 0$, we have

$$
\left\langle(I-f) Q(f), J_{\varphi}(Q(f)-p)\right\rangle \leq 0 \text {. }
$$

Since $J_{\varphi}(x)=\frac{\varphi(\|x\|)}{\|x\|} J(x)$ for any $x \neq 0$, we have

$$
\langle(I-f) Q(f), J(Q(f)-p)\rangle \leq 0
$$

This completes the proof.

Recall that a gauge is a continuous strictly increasing function $\varphi:[0, \infty) \rightarrow[0, \infty)$ such that $\varphi(0)=0$ and $\varphi(t) \rightarrow \infty$ as $t \rightarrow \infty$. The duality mapping $J_{\varphi}: X \rightarrow X^{*}$ associated to a gauge $\varphi$ is defined by

$$
J_{\varphi}(x)=\left\{x^{*} \in X^{*}:\left\langle x, x^{*}\right\rangle=\|x\| \varphi(\|x\|),\left\|x^{*}\right\|=\varphi(\|x\|)\right\}, \quad \forall x \in X .
$$

Following Browder [37], we say that a Banach space $E$ has a weakly continuous duality mapping if there exists a gauge $\varphi$ for which the duality mapping $J_{\varphi}(x)$ is single-valued and weak-to-weak" sequentially continuous (i.e., if $\left\{x_{n}\right\}$ is a sequence in $E$ weakly convergent to a point $x$, then the sequence $J_{\varphi}\left(x_{n}\right)$ converges weakly" to $\left.J_{\varphi}\right)$. It is known that $l^{p}$ has a weakly continuous duality mapping with a gauge function $\varphi(t)=t^{p-1}$ for all $1<p<\infty$. Set

$$
\Phi(t)=\int_{0}^{t} \varphi(\tau) d_{\tau}, \quad \forall t \geq 0 .
$$

Then

$$
J_{\varphi}(x)=\partial \Phi(\|x\|), \quad \forall x \in X
$$

where $\partial$ denotes the sub-differential in the sense of convex analysis.

The first part of the next lemma is an immediate consequence of the sub-differential inequality and the proof of the second part can be found in [38]. 
Lemma 2.5 Assume that a Banach space $E$ has a weakly continuous duality mapping $J_{\varphi}$ with a gauge $\varphi$.

(i) For all $x, y \in E$, the following inequality holds:

$$
\Phi(\|x+y\|) \leq \Phi(\|x\|)+\left\langle y, J_{\varphi}(x+y)\right\rangle .
$$

In particular, for all $x, y \in E$

$$
\|x+y\|^{2} \leq\|x\|^{2}+2\langle y, J(x+y)\rangle
$$

(ii) Assume that a sequence $\left\{x_{n}\right\}$ in $E$ converges weakly to a point $x \in E$.

Then the following identity holds:

$$
\limsup _{n \rightarrow \infty} \Phi\left(\left\|x_{n}-y\right\|\right)=\limsup _{n \rightarrow \infty} \Phi\left(\left\|x_{n}-x\right\|\right)+\Phi(\|y-x\|), \quad \forall x, y \in E .
$$

Lemma 2.6 [39] Let $\left\{x_{n}\right\}$ and $\left\{y_{n}\right\}$ be bounded sequences in a Banach space $X$ and let $\left\{\beta_{n}\right\}$ be a sequence in $[0,1]$ with $0<\liminf _{n \rightarrow \infty} \beta_{n} \leq \limsup _{n \rightarrow \infty} \beta_{n}<1$. Suppose that $x_{n+1}=$ $\left(1-\beta_{n}\right) y_{n}+\beta_{n} x_{n}$ for all integers $n \geq 0$ and

$$
\limsup _{n \rightarrow \infty}\left(\left\|y_{n+1}-y_{n}\right\|-\left\|x_{n+1}-x_{n}\right\|\right) \leq 0
$$

Then $\lim _{n \rightarrow \infty}\left\|y_{n}-x_{n}\right\|=0$.

Lemma 2.7 [40] Assume that $\left\{\alpha_{n}\right\}$ is a sequence of nonnegative real numbers such that

$$
\alpha_{n+1} \leq\left(1-\gamma_{n}\right) \alpha_{n}+\delta_{n}
$$

where $\left\{\gamma_{n}\right\}$ is a sequence in $(0,1)$ and $\left\{\delta_{n}\right\}$ is a sequence such that

(i) $\sum_{n=1}^{\infty} \gamma_{n}=\infty$;

(ii) $\lim \sup _{n \rightarrow \infty} \delta_{n} / \gamma_{n} \leq 0$ or $\sum_{n=1}^{\infty}\left|\delta_{n}\right|<\infty$.

Then $\lim _{n \rightarrow \infty} \alpha_{n}=0$.

The following lemma can be obtained from Chang et al. [23]. For the sake of completeness, we still give the proof.

Lemma 2.8 Let $C$ be a nonempty closed convex subset of a strictly convex Banach space $E$, let $\left\{T_{i}: C \rightarrow C\right\}$ be a family of infinitely nonexpansive mappings with $\bigcap_{i=1}^{\infty} F\left(T_{i}\right) \neq \emptyset$, let $\left\{\gamma_{n}\right\}$ be a real sequence such that $0<\gamma_{n} \leq b<1$ for each $n \geq 1$. If $K$ is any bounded subset of $C$, then $\lim _{n \rightarrow \infty} \sup _{x \in K}\left\|W x-W_{n} x\right\|=0$.

Proof Let $p \in \bigcap_{i=1}^{\infty} F\left(T_{i}\right)$. Since $K$ is a bounded subset of $C$, there exists an $M>0$ such that $\sup _{x \in K}\|x-p\| \leq M$. It follows that

$$
\begin{aligned}
\left\|W_{n+1} x-W_{n} x\right\| & =\left\|\gamma_{1} T_{1} U_{n+1,2} x+\left(1-\gamma_{1}\right) x-\gamma_{1} T_{1} U_{n, 2} x-\left(1-\gamma_{1}\right) x\right\| \\
& \leq \gamma_{1}\left\|U_{n+1,2} x-U_{n, 2} x\right\| \\
& =\gamma_{1}\left\|\gamma_{2} T_{2} U_{n+1,3} x+\left(1-\gamma_{2}\right) x-\gamma_{2} T_{2} U_{n, 3} x-\left(1-\gamma_{2}\right) x\right\|
\end{aligned}
$$




$$
\begin{aligned}
& \leq \gamma_{1} \gamma_{2}\left\|U_{n+1,3} x-U_{n, 3} x\right\| \\
& \vdots \\
& \leq \prod_{i=1}^{n} \gamma_{i}\left\|U_{n+1, n+1} x-U_{n, n+1} x\right\| \\
& \leq \prod_{i=1}^{n+1} \gamma_{i}\left(\left\|T_{n+1} x-p\right\|+\|p-x\|\right) \\
& \leq 2 \prod_{i=1}^{n+1} \gamma_{i} M .
\end{aligned}
$$

Since $0<\gamma_{n} \leq b<1$, for any given $\epsilon>0$, there exists a positive integer $n_{0}$ such that

$$
b^{n_{0}+1} \leq \frac{\epsilon(1-b)}{2 M} .
$$

For any positive integers $m>n>n_{0}$, we find that

$$
\begin{aligned}
\left\|W_{m} x-W_{n} x\right\| & \leq \sum_{j=n}^{m-1}\left\|W_{j} x-W_{j} x\right\| \\
& \leq 2 M \sum_{j=n}^{m-1} \prod_{i=1}^{j+1} \gamma_{i} \\
& \leq 2 M \sum_{j=n}^{m-1} b^{j+1} \\
& \leq \frac{2 M b^{n+1}}{1-b} \\
& \leq \epsilon, \quad \forall x \in K .
\end{aligned}
$$

Letting $m \rightarrow \infty$, we find that

$$
\left\|W x-W_{n} x\right\| \leq \epsilon, \quad \forall n \geq n_{0} .
$$

This implies that $\lim _{n \rightarrow \infty} \sup _{x \in K}\left\|W x-W_{n} x\right\|=0$.

\section{Main results}

Theorem 3.1 Let E be a reflexive and strictly convex Banach space E which enjoys a weakly continuous duality map $J_{\varphi}(x)$ with gauge $\varphi$ and let $A$ be an m-accretive operator in $E$ with the domain $D(A)$. Assume that $\overline{D(A)}$ is convex. Let $T_{i}$ be a nonexpansive mapping from $C=: \overline{D(A)}$ into itself for $i \in \mathbb{Z}^{+}$. Let $f \in \Pi_{C}$ with the coefficient $(0<\alpha<1)$ and $J_{r}=(I+r A)^{-1}$ for some $r>0$. Assume that $\Omega:=F\left(J_{r} W\right)=F\left(J_{r}\right) \cap F(W) \neq \emptyset$, where $W$ is a mapping defined by (2.2). Let $\left\{x_{n}\right\}$ be a sequence generated in the following iterative algorithm:

$$
\left\{\begin{array}{l}
x_{0} \in C, \\
y_{n}=\beta_{n} x_{n}+\left(1-\beta_{n}\right) J_{r} W_{n} x_{n}, \\
x_{n+1}=\alpha_{n} f\left(y_{n}\right)+\left(1-\alpha_{n}\right) y_{n}, \quad n \geq 0,
\end{array}\right.
$$


where $W_{n}$ is generated in (2.1), $\left\{\alpha_{n}\right\}$ and $\left\{\beta_{n}\right\}$ are real number sequences in $(0,1)$ satisfying the following restrictions:

(a) $\sum_{n=0}^{\infty} \alpha_{n}=\infty, \lim _{n \rightarrow \infty} \alpha_{n}=0$;

(b) $0<\liminf _{n \rightarrow \infty} \beta_{n} \leq \lim \sup _{n \rightarrow \infty} \beta_{n}<1$.

Then $\left\{x_{n}\right\}$ strongly converges to $Q(f) \in \Omega$, where $Q: \Pi_{C} \rightarrow \Omega$ is defined by (2.3).

Proof First we prove that sequences $\left\{x_{n}\right\}$ and $\left\{y_{n}\right\}$ are bounded. Fixing $p \in \Omega$, we see that

$$
\begin{aligned}
\left\|y_{n}-p\right\| & \leq \beta_{n}\left\|x_{n}-p\right\|+\left(1-\beta_{n}\right)\left\|J_{r} W_{n} x_{n}-p\right\| \\
& \leq\left\|x_{n}-p\right\| .
\end{aligned}
$$

It follows that

$$
\begin{aligned}
\left\|x_{n+1}-p\right\| & =\left\|\alpha_{n}\left(f\left(y_{n}\right)-p\right)+\left(1-\alpha_{n}\right)\left(y_{n}-p\right)\right\| \\
& \leq \alpha_{n}\left\|f\left(y_{n}\right)-p\right\|+\left(1-\alpha_{n}\right)\left\|y_{n}-p\right\| \\
& \leq\left[1-\alpha_{n}(1-\alpha)\right]\left\|x_{n}-p\right\|+\alpha_{n}\|f(p)-p\| \\
& \leq \max \left\{\left\|x_{n}-p\right\|, \frac{\|f(p)-p\|}{1-\alpha}\right\} .
\end{aligned}
$$

This in turn implies that

$$
\left\|x_{n}-p\right\| \leq \max \left\{\left\|x_{0}-p\right\|, \frac{\|p-f(p)\|}{1-\alpha}\right\}
$$

which gives that the sequence $\left\{x_{n}\right\}$ is bounded, so is $\left\{y_{n}\right\}$.

Next, we prove that $\left\|x_{n+1}-x_{n}\right\| \rightarrow 0$ as $n \rightarrow \infty$. Putting $l_{n}=\frac{x_{n+1}-\beta_{n} x_{n}}{1-\beta_{n}}$, we have

$$
x_{n+1}=\left(1-\beta_{n}\right) l_{n}+\beta_{n} x_{n} .
$$

In the light of

$$
\begin{aligned}
l_{n+1}-l_{n}= & \frac{\alpha_{n+1} f\left(y_{n+1}\right)+\left(1-\alpha_{n+1}\right) y_{n+1}-\beta_{n+1} x_{n+1}}{1-\beta_{n+1}}-\frac{\alpha_{n} f\left(y_{n}\right)+\left(1-\alpha_{n}\right) y_{n}-\beta_{n} x_{n}}{1-\beta_{n}} \\
= & \frac{\alpha_{n+1}\left(f\left(y_{n+1}\right)-y_{n+1}\right)}{1-\beta_{n+1}}-\frac{\alpha_{n}\left(f\left(y_{n}\right)-y_{n}\right)}{1-\beta_{n}} \\
& +J_{r} W_{n+1} x_{n+1}-J_{r} W_{n+1} x_{n}+J_{r} W_{n+1} x_{n}-J_{r} W_{n} x_{n},
\end{aligned}
$$

we obtain that

$$
\begin{aligned}
\left\|l_{n+1}-l_{n}\right\| \leq & \frac{\alpha_{n+1}}{1-\beta_{n+1}}\left\|f\left(y_{n+1}\right)-y_{n+1}\right\|+\frac{\alpha_{n}}{1-\beta_{n}}\left\|y_{n}-f\left(y_{n}\right)\right\| \\
& +\left\|x_{n+1}-x_{n}\right\|+\left\|J_{r} W_{n+1} x_{n}-J_{r} W_{n} x_{n}\right\| \\
\leq & \frac{\alpha_{n+1}}{1-\beta_{n+1}}\left\|f\left(y_{n+1}\right)-y_{n+1}\right\|+\frac{\alpha_{n}}{1-\beta_{n}}\left\|y_{n}-f\left(y_{n}\right)\right\| \\
& +\left\|x_{n+1}-x_{n}\right\|+\left\|W_{n+1} x_{n}-W_{n} x_{n}\right\| .
\end{aligned}
$$


Since $T_{i}$ and $U_{n, i}$ are nonexpansive, we have

$$
\begin{aligned}
\left\|W_{n+1} x_{n}-W_{n} x_{n}\right\| & =\left\|\gamma_{1} T_{1} U_{n+1,2} x_{n}-\gamma_{1} T_{1} U_{n, 2} x_{n}\right\| \\
& \leq \gamma_{1}\left\|U_{n+1,2} x_{n}-U_{n, 2} x_{n}\right\| \\
& =\gamma_{1}\left\|\gamma_{2} T_{2} U_{u+1,3} x_{n}-\gamma_{2} T_{2} U_{n, 3} x_{n}\right\| \\
& \leq \gamma_{1} \gamma_{2}\left\|U_{u+1,3} x_{n}-U_{n, 3} x_{n}\right\| \\
& \leq \cdots \\
& \leq \gamma_{1} \gamma_{2} \cdots \gamma_{n}\left\|U_{n+1, n+1} x_{n}-U_{n, n+1} x_{n}\right\| \\
& \leq M_{1} \prod_{i=1}^{n} \gamma_{i},
\end{aligned}
$$

where $M_{1} \geq 0$ is an appropriate constant such that

$$
\left\|U_{n+1, n+1} x_{n}-U_{n, n+1} x_{n}\right\| \leq M_{1}
$$

for all $n \geq 0$. Substituting (3.4) into (3.3), we have

$$
\left\|l_{n+1}-l_{n}\right\|-\left\|x_{n+1}-x_{n}\right\| \leq \frac{\alpha_{n+1}}{1-\beta_{n+1}}\left\|f\left(y_{n+1}\right)-y_{n+1}\right\|+\frac{\alpha_{n}}{1-\beta_{n}}\left\|y_{n}-f\left(y_{n}\right)\right\|+M_{1} \prod_{i=1}^{n} \gamma_{i}
$$

In view of conditions (a) and (b), we get that

$$
\limsup _{n \rightarrow \infty}\left(\left\|l_{n+1}-l_{n}\right\|-\left\|x_{n+1}-x_{n}\right\|\right) \leq 0 .
$$

We can obtain from Lemma 2.6 that $\lim _{n \rightarrow \infty}\left\|l_{n}-x_{n}\right\|=0$ easily. On the other hand, we see from (3.1) that

$$
x_{n+1}-x_{n}=\left(1-\beta_{n}\right)\left(l_{n}-x_{n}\right) \text {. }
$$

This implies that

$$
\lim _{n \rightarrow \infty}\left\|x_{n+1}-x_{n}\right\|=0
$$

Next, we prove that $\lim _{n \rightarrow \infty}\left\|J_{r} W x_{n}-x_{n}\right\|=0$. In view of

$$
x_{n+1}-y_{n}=\alpha_{n}\left(f\left(y_{n}\right)-y_{n}\right) \text {, }
$$

we obtain that

$$
\lim _{n \rightarrow \infty}\left\|x_{n+1}-y_{n}\right\|=0
$$

On the other hand, we have

$$
\left\|y_{n}-x_{n}\right\| \leq\left\|x_{n}-x_{n+1}\right\|+\left\|x_{n+1}-y_{n}\right\| .
$$


In view of (3.5) and (3.6), we have

$$
\lim _{n \rightarrow \infty}\left\|y_{n}-x_{n}\right\|=0
$$

Notice that

$$
\begin{aligned}
\left\|J_{r} W_{n} x_{n}-x_{n}\right\| & \leq\left\|x_{n}-y_{n}\right\|+\left\|y_{n}-J_{r} W_{n} x_{n}\right\| \\
& \leq\left\|x_{n}-y_{n}\right\|+\beta_{n}\left\|x_{n}-J_{r} W_{n} x_{n}\right\| .
\end{aligned}
$$

This implies that

$$
\left(1-\beta_{n}\right)\left\|J_{r} W_{n} x_{n}-x_{n}\right\| \leq\left\|x_{n}-y_{n}\right\|
$$

From condition (b) and (3.7), we obtain that

$$
\lim _{n \rightarrow \infty}\left\|J_{r} W_{n} x_{n}-x_{n}\right\|=0 .
$$

On the other hand, we have

$$
\begin{aligned}
\left\|J_{r} W x_{n}-x_{n}\right\| & \leq\left\|J_{r} W x_{n}-J_{r} W_{n} x_{n}\right\|+\left\|J_{r} W_{n} x_{n}-x_{n}\right\| \\
& \leq\left\|W x_{n}-W_{n} x_{n}\right\|+\left\|J_{r} W_{n} x_{n}-x_{n}\right\| .
\end{aligned}
$$

In view of Lemma 2.8, we find that

$$
\lim _{n \rightarrow \infty}\left\|W x_{n}-W_{n} x_{n}\right\|=0
$$

This in turn implies that

$$
\lim _{n \rightarrow \infty}\left\|J_{r} W x_{n}-x_{n}\right\|=0
$$

Next, we show $x_{n} \rightarrow Q(f)$ as $n \rightarrow \infty$. To show it, we first prove that

$$
\limsup _{n \rightarrow \infty}\left\langle(I-f) Q(f), J_{\varphi}\left(Q(f)-x_{n}\right)\right\rangle \leq 0
$$

In view of Lemma 2.4, we have the sunny nonexpansive retraction $Q: \Pi_{C} \rightarrow \Omega$. Take a subsequence $\left\{x_{n_{k}}\right\}$ of $\left\{x_{n}\right\}$ such that

$$
\limsup _{n \rightarrow \infty}\left\langle(I-f) Q(f), J_{\varphi}\left(Q(f)-x_{n}\right)\right\rangle=\lim _{k \rightarrow \infty}\left\langle(I-f) Q(f), J_{\varphi}\left(Q(f)-x_{n_{k}}\right)\right\rangle .
$$

Since $E$ is reflexive, we may further assume that $x_{n_{k}} \rightarrow \bar{x}$ for some $\bar{x} \in C$. Since $J_{\varphi}$ is weakly continuous, we obtain from Lemma 2.5 that

$$
\limsup _{n \rightarrow \infty} \Phi\left(\left\|x_{n_{k}}-x\right\|\right)=\limsup _{n \rightarrow \infty} \Phi\left(\left\|x_{n_{k}}-\bar{x}\right\|\right)+\Phi(\|x-\bar{x}\|), \quad \forall x \in E .
$$


Put

$$
g(x)=\limsup _{k \rightarrow \infty} \Phi\left(\left\|x_{n_{k}}-x\right\|\right), \quad \forall x \in E .
$$

It follows that

$$
g(x)=g(\bar{x})+\Phi(\|x-\bar{x}\|), \quad \forall x \in E .
$$

With the aid of (3.9), we arrive at

$$
\begin{aligned}
g\left(J_{r} W \bar{x}\right) & =\limsup _{k \rightarrow \infty} \Phi\left(\left\|x_{n_{k}}-J_{r} W \bar{x}\right\|\right)=\limsup _{k \rightarrow \infty} \Phi\left(\left\|J_{r} W x_{n_{k}}-J_{r} W \bar{x}\right\|\right) \\
& \leq \limsup _{k \rightarrow \infty} \Phi\left(\left\|x_{n_{k}}-\bar{x}\right\|\right) \\
& =g(\bar{x}) .
\end{aligned}
$$

Notice that

$$
g\left(J_{r} W \bar{x}\right)=g(\bar{x})+\Phi\left(\left\|J_{r} W \bar{x}-\bar{x}\right\|\right) .
$$

From (3.12) and (3.13), we find that

$$
\Phi\left(\left\|J_{r} W \bar{x}-\bar{x}\right\|\right) \leq 0 .
$$

This implies that $J_{r} W \bar{x}=\bar{x}$. And hence $\bar{x} \in F\left(J_{r} W\right)$. That is, $\bar{x} \in \Omega$. Since $Q$ is the sunny nonexpansive retraction from $\Pi_{C}$ onto $F$, we have from (3.11)

$$
\limsup _{n \rightarrow \infty}\left\langle(I-f) Q(f), J_{\varphi}\left(Q(f)-x_{n}\right)\right\rangle=\left\langle(I-f) Q(f), J_{\varphi}(Q(f)-\bar{x})\right\rangle \leq 0 .
$$

This shows that (3.10) holds. It follows from Lemma 2.5 that

$$
\begin{aligned}
\Phi & \left\|x_{n+1}-Q(f)\right\| \\
= & \Phi\left(\left\|\alpha_{n}\left(f\left(x_{n}\right)-f(Q(f))\right)+\alpha_{n}(f(Q(f))-Q(f))+\left(1-\alpha_{n}\right)\left(y_{n}-Q(f)\right)\right\|\right) \\
\leq & \Phi\left(\alpha_{n}\left\|f\left(x_{n}\right)-f(Q(f))\right\|+\left(1-\alpha_{n}\right)\left\|y_{n}-Q(f)\right\|\right) \\
& +\alpha_{n}\left\langle f(Q(f))-Q(f), J_{\varphi}\left(x_{n+1}-Q(f)\right)\right\rangle \\
\leq & \Phi\left(\left(1-\alpha_{n}(1-\alpha)\right)\left\|x_{n}-Q(f)\right\|\right) \\
& +\alpha_{n}\left\{f(Q(f))-Q(f), J_{\varphi}\left(x_{n+1}-Q(f)\right)\right\rangle \\
\leq & \left(1-\alpha_{n}(1-\alpha)\right) \Phi\left(\left\|x_{n}-Q(f)\right\|\right) \\
& +\alpha_{n}\left\langle f(Q(f))-Q(f), J_{\varphi}\left(x_{n+1}-Q(f)\right)\right\rangle .
\end{aligned}
$$

We find that $\left\|x_{n}-Q(f)\right\| \rightarrow 0$ as $n \rightarrow \infty$ from Lemma 2.7. That is, $x_{n} \rightarrow Q(f)$. This completes the proof. 
Remark 3.2 Taking $T_{i}=I$, the identity mapping, $\forall i \geq 1$, we see that $W_{n}=I$. Then the strict convexity of $E$ in Theorem 3.1 may not be needed.

Corollary 3.3 Let E be a reflexive Banach space E which enjoys a weakly continuous duality map $J_{\varphi}(x)$ with gauge $\varphi$ and $A$ be an m-accretive operator in $E$ with the domain $D(A)$. Assume that $\overline{D(A)}$ is convex. Let $f \in \Pi_{\overline{D(A)}}$ with the coefficient $(0<\alpha<1)$ and $J_{r}=(I+r A)^{-1}$ for some $r>0$. Assume that $A^{-1}(0) \neq \emptyset$. Let $\left\{x_{n}\right\}$ be a sequence generated in the following iterative algorithm:

$$
\left\{\begin{array}{l}
x_{0} \in A^{-1}(0), \\
y_{n}=\beta_{n} x_{n}+\left(1-\beta_{n}\right) J_{r} x_{n}, \\
x_{n+1}=\alpha_{n} f\left(y_{n}\right)+\left(1-\alpha_{n}\right) y_{n}, \quad n \geq 0,
\end{array}\right.
$$

where $\left\{\alpha_{n}\right\}$ and $\left\{\beta_{n}\right\}$ are real number sequences in $(0,1)$ satisfying the following restrictions:

(a) $\sum_{n=0}^{\infty} \alpha_{n}=\infty, \lim _{n \rightarrow \infty} \alpha_{n}=0$;

(b) $0<\liminf _{n \rightarrow \infty} \beta_{n} \leq \limsup _{n \rightarrow \infty} \beta_{n}<1$.

Then $\left\{x_{n}\right\}$ strongly converges to $Q(f) \in A^{-1}(0)$, where $Q: \Pi_{\overline{D(A)}} \rightarrow A^{-1}(0)$ is defined by (2.3).

If $f(x)=u$, where $u$ is a fixed element in $\overline{D(A)}$, then Theorem 3.1 is reduced to the following.

Corollary 3.4 Let E be a reflexive and strictly convex Banach space E which enjoys a weakly continuous duality map $J_{\varphi}(x)$ with gauge $\varphi$ and $A$ be an m-accretive operator in $E$ with the domain $D(A)$. Assume that $\overline{D(A)}$ is convex. Let $T_{i}$ be a nonexpansive mapping from $C=: \overline{D(A)}$ into itself for $i \in \mathbb{Z}^{+}$. Let $J_{r}=(I+r A)^{-1}$ for some $r>0$. Assume that $\Omega:=F\left(J_{r} W\right)=F\left(J_{r}\right) \cap F(W) \neq \emptyset$, where $W$ is a mapping defined by (2.2). Let $\left\{x_{n}\right\}$ be a sequence generated in the following iterative algorithm:

$$
\left\{\begin{array}{l}
x_{0} \in C, \\
y_{n}=\beta_{n} x_{n}+\left(1-\beta_{n}\right) J_{r} W_{n} x_{n}, \\
x_{n+1}=\alpha_{n} u+\left(1-\alpha_{n}\right) y_{n}, \quad n \geq 0,
\end{array}\right.
$$

where $W_{n}$ is generated in (2.1), $\left\{\alpha_{n}\right\}$ and $\left\{\beta_{n}\right\}$ are real number sequences in $(0,1)$ satisfying the following restrictions:

(a) $\sum_{n=0}^{\infty} \alpha_{n}=\infty, \lim _{n \rightarrow \infty} \alpha_{n}=0$;

(b) $0<\liminf _{n \rightarrow \infty} \beta_{n} \leq \limsup _{n \rightarrow \infty} \beta_{n}<1$.

Then $\left\{x_{n}\right\}$ strongly converges to $Q(u) \in \Omega$, where $Q: \Pi_{C} \rightarrow \Omega$ is defined by (2.3).

If $A=I$, then Theorem 3.1 is reduced to the following.

Corollary 3.5 Let E be a reflexive and strictly convex Banach space E which enjoys a weakly continuous duality map $J_{\varphi}(x)$ with gauge $\varphi$ and let $C$ be a closed and convex subset of $E$. Let $T_{i}$ be a nonexpansive mapping from $C$ into itself for $i \in \mathbb{Z}^{+}$. Let $f \in \Pi_{C}$ with the coeffcient $(0<\alpha<1)$. Assume that $\Omega:=\bigcap_{i=1}^{\infty} F\left(T_{i}\right) \neq \emptyset$. Let $\left\{x_{n}\right\}$ be a sequence generated in the 
following iterative algorithm:

$$
\left\{\begin{array}{l}
x_{0} \in C, \\
y_{n}=\beta_{n} x_{n}+\left(1-\beta_{n}\right) W_{n} x_{n}, \\
x_{n+1}=\alpha_{n} f\left(y_{n}\right)+\left(1-\alpha_{n}\right) y_{n}, \quad n \geq 0,
\end{array}\right.
$$

where $W_{n}$ is generated in (2.1), $\left\{\alpha_{n}\right\}$ and $\left\{\beta_{n}\right\}$ are real number sequences in $(0,1)$ satisfying the following restrictions:

(a) $\sum_{n=0}^{\infty} \alpha_{n}=\infty, \lim _{n \rightarrow \infty} \alpha_{n}=0$;

(b) $0<\liminf _{n \rightarrow \infty} \beta_{n} \leq \limsup _{n \rightarrow \infty} \beta_{n}<1$.

Then $\left\{x_{n}\right\}$ strongly converges to $Q(f) \in \Omega$, where $Q: \Pi_{C} \rightarrow \Omega$ is defined by (2.3).

\section{Competing interests}

The authors declare that they have no competing interests.

\section{Authors' contributions}

Both authors contributed equally and significantly in writing this paper. Both authors read and approved the final manuscript.

\section{Author details}

${ }^{1}$ School of Mathematics and Information Science, North China University of Water Resources and Electric Power, Zhengzhou, 450011, China. ${ }^{2}$ College of Science, Hebei University of Engineering, Handan, 056038, China.

\section{Acknowledgements}

The authors are grateful to the reviewers and editor for their hard work for this article.

\section{Received: 16 March 2013 Accepted: 17 June 2013 Published: 3 July 2013}

\section{References}

1. Dhage, BC, Jadhav, NS: Differential inequalities and comparison theorems for first order hybrid integro-differential equations. Adv. Inequal. Appl. 2, 61-80 (2013)

2. Ansari, QH, Schaible, S, Yao, JC: The system of generalized vector equilibrium problems with applications. J. Glob. Optim. 22, 3-16 (2002)

3. Noor, MA, Noor, Kl, Waseem, M: Decomposition method for solving system of linear equations. Eng. Math. Lett. 2, 34-41 (2013)

4. Qin, X, Chang, SS, Cho, YJ: Iterative methods for generalized equilibrium problems and fixed point problems with applications. Nonlinear Anal. 11, 2963-2972 (2010)

5. Abdel-Salam, HS, Al-Khaled, K: Variational iteration method for solving optimization problems. J. Math. Comput. Sci. 2, 1475-1497 (2012)

6. Park, S: On generalizations of the Ekeland-type variational principles. Nonlinear Anal. 39, 881-889 (2000)

7. Al-Bayati, AY, Al-Kawaz, RZ: A new hybrid WC-FR conjugate gradient-algorithm with modified secant condition for unconstrained optimization. J. Math. Comput. Sci. 2, 937-966 (2012)

8. Tanaka, Y: Constructive proof of the existence of Nash equilibrium in a strategic game with sequentially locally non-constant payoff functions. Adv. Fixed Point Theory 2, 398-416 (2012)

9. Khanh, PQ, Luu, LM: On the existence of solutions to vector quasivariational inequalities and quasicomplementarity problems with applications to traffic network equilibria. J. Optim. Theory Appl. 123, 533-548 (2004)

10. Husain, S, Gupta, S: A resolvent operator technique for solving generalized system of nonlinear relaxed cocoercive mixed variational inequalities. Adv. Fixed Point Theory 1, 18-28 (2011)

11. liduka, H: Fixed point optimization algorithm and its application to network bandwidth allocation. J. Comput. Appl. Math. 236, 1733-1742 (2012)

12. Shen, J, Pang, LP: An approximate bundle method for solving variational inequalities. Comm. Optim. Theory 1, 1-18 (2012)

13. Shimoji, K, Takahashi, W: Strong convergence to common fixed points of infinite nonexpansive mappings and applications. Taiwan. J. Math. 5, 387-404 (2001)

14. Cho, SY, Kang, SM: Approximation of common solutions of variational inequalities via strict pseudocontractions. Acta Math. Sci. 32, 1607-1618 (2012)

15. Cho, SY, Kang, SM: Approximation of fixed points of pseudocontraction semigroups based on a viscosity iterative process. Appl. Math. Lett. 24, 224-228 (2011)

16. Kim, JK: Strong convergence theorems by hybrid projection methods for equilibrium problems and fixed point problems of the asymptotically quasi- $\boldsymbol{\phi}$-nonexpansive mappings. Fixed Point Theory Appl. 2011, 10 (2011)

17. Qin, X, Cho, YJ, Kang, SM: Convergence theorems of common elements for equilibrium problems and fixed point problems in Banach spaces. J. Comput. Appl. Math. 225, 20-30 (2009) 
18. Qin, X, Cho, SY, Kang, SM: On hybrid projection methods for asymptotically quasi- $\phi$-nonexpansive mappings. Appl. Math. Comput. 215, 3874-3883 (2010)

19. Zegeye, H, Shahzad, N: Strong convergence theorem for a common point of solution of variational inequality and fixed point problem. Adv. Fixed Point Theory 2, 374-397 (2012)

20. Qin, X, Cho, SY, Kang, SM: Iterative algorithms for variational inequality and equilibrium problems with applications. J. Glob. Optim. 48, 423-445 (2010)

21. Saini, RK, Kumar, M: Common fixed point of expansion type maps in cone metric space using implicit relations. Adv. Fixed Point Theory 2, 326-339 (2012)

22. Qin, X, Cho, SY, Kang, SM: Strong convergence of shrinking projection methods for quasi- $\phi$-nonexpansive mappings and equilibrium problems. J. Comput. Appl. Math. 234, 750-760 (2010)

23. Luo, H, Wang, Y: Iterative approximation for the common solutions of a infinite variational inequality system for inverse-strongly accretive mappings. J. Math. Comput. Sci. 2, 1660-1670 (2012)

24. Qing, Y, Cho, SY, Shang, M: Strong convergence of an iterative process for a family of strictly pseudocontractive mappings. Fixed Point Theory Appl. 2013, 117 (2013)

25. Reich, S: Strong convergence theorems for resolvents of accretive operators in Banach spaces. J. Math. Anal. Appl. 75, 287-292 (1980)

26. Xu, HK: Strong convergence of an iterative method for nonexpansive and accretive operators. J. Math. Anal. Appl. 314, 631-643 (2006)

27. Kim, TH, Xu, HK: Strong convergence of modified Mann iterations. Nonlinear Anal. 61, 51-60 (2005)

28. Kotzer, T, Cohen, N, Shamir, J: Image restoration by a novel method of parallel projection onto constraint sets. Opt. Lett. 20, 1172-1174 (1995)

29. Sezan, Ml, Stark, H: Application of convex projection theory to image recovery in tomograph and related areas. In: Stark, H (ed.) Image Recovery: Theory and Application, pp. 155-270. Academic Press, Orlando (1987)

30. Censor, Y, Zenios, SA: Parallel Optimization. Theory, Algorithms, and Applications, Numerical Mathematics and Scientific Computation. Oxford University Press, New York (1997)

31. Takahashi, W, Shimoji, K: Convergence theorems for nonexpansive mappings and feasibility problems. Math. Comput. Model. 32, 1463-1471 (2000)

32. Qin, X, Su, Y: Approximation of a zero point of accretive operator in Banach spaces. J. Math. Anal. Appl. 329, 415-424 (2007)

33. Chang, SS, Lee, HWJ, Chan, CK: A new method for solving equilibrium problem fixed point problem and variational inequality problem with application to optimization. Nonlinear Anal. 70, 3307-3319 (2009)

34. Chen, R, Zhu, Z: Viscosity approximation fixed points for nonexpansive and $m$-accretive operators. Fixed Point Theory Appl. 2006, 81325 (2006)

35. Ceng, LC, Petrusel, A, Wong, MM: Hybrid viscosity iterative approximation of zeros of $m$-accretive operators in Banach spaces. Taiwan. J. Math. 15, 2459-2481 (2011)

36. Qin, X, Kang, SM, Cho, YJ: Approximating zeros of monotone operators by proximal point algorithms. J. Glob. Optim. 46, 75-87 (2010)

37. Browder, FE: Fixed point theorems for noncompact mappings in Hilbert spaces. Proc. Natl. Acad. Sci. USA 53 , $1272-1276(1965)$

38. Lim, TC, Xu, HK: Fixed point theorems for asymptotically nonexpansive mappings. Nonlinear Anal. 22, 1345-1355 (1994)

39. Suzuki, T: Strong convergence of Krasnoselskii and Mann's type sequences for one-parameter nonexpansive semigroups without Bochner integrals. J. Math. Anal. Appl. 305, 227-239 (2005)

40. Liu, LS: Ishikawa and Mann iteration process with errors for nonlinear strongly accretive mappings in Banach spaces, J. Math. Anal. Appl. 194, 114-125 (1995)

\section{Submit your manuscript to a SpringerOpen ${ }^{\ominus}$ journal and benefit from:}

- Convenient online submission

Rigorous peer review

- Immediate publication on acceptance

- Open access: articles freely available online

- High visibility within the field

- Retaining the copyright to your article 